\title{
Effect of salinity on microbial methane oxidation in freshwater and marine environments
}

\author{
Roman Osudar ${ }^{1,2}$, Karl-Walter Klings ${ }^{1}$, Dirk Wagner ${ }^{2}$, Ingeborg Bussmann ${ }^{1, *}$ \\ ${ }^{1}$ Alfred Wegener Institute, Helmholtz Centre for Polar and Marine Research, Kurpromenade 201, 27498 Helgoland, Germany \\ ${ }^{2}$ GFZ German Research Centre for Geosciences, Helmholtz Center Potsdam, Section 5.3 Geomicrobiology, Telegrafenberg, \\ 14473 Potsdam, Germany
}

\begin{abstract}
Salinity is an important environmental control of aerobic methane oxidation, which reduces the emission of the potent greenhouse gas methane into the atmosphere. The effect of salinity on methane oxidation is especially severe in river estuaries and adjacent coastal waters, which are important sources of methane emission and, at the same time, are usually characterized by pronounced salinity gradients. Using methane oxidation rates determined by a radiotracer technique as a measure of methanotrophic activity, we tested the effect of immediate and gradual salinity changes on pure cultures of methanotrophic bacteria, and natural freshwater (Elbe River) and natural marine (North Sea) methanotrophic populations. According to our results, Methylomonas sp. and Methylosinus trichosporium are resistant to an increase in salinity, whereas Methylovulum sp. and Methylobacter luteus are sensitive to such an increase. Natural methanotrophic populations from freshwater are more resistant to an increase in salinity than those from marine water are to a decrease in salinity. In contrast to an immediate change of salinity, gradual change (1.25 PSU d ${ }^{-1}$ ) can attenuate salinity stress. Experiments with the natural populations revealed different reactions to changes in salinity; thus, we assume that the initial composition of the methanotrophic population, i.e. the ratio of sensitive versus resistant strains, also governs the community response to salinity stress.
\end{abstract}

KEY WORDS: Microbial methane oxidation · Salinity · Osmoregulation

\section{INTRODUCTION}

Methane is an important trace gas, responsible for approximately $20 \%$ of the greenhouse effect (Cicerone \& Oremland 1988, IPCC 2014). Its atmospheric concentration has been steadily increasing over the past $300 \mathrm{yr}$, mostly owing to anthropogenic activity (Singh et al. 2010). Sources of methane emission into the atmosphere can be divided into 2 categories: anthropogenic $(\sim 60 \%)$ and natural $(\sim 40 \%)$ (Kirschke et al. 2013). Freshwater environments, such as lakes and rivers, and near-shore marine environments, such as shelf areas and estuaries, are important natural methane sources (Bastviken et al. 2011, Kirschke et al. 2013, Hamdan \& Wickland

\footnotetext{
*Corresponding author: ingeborg.bussmann@awi.de
}

2016). According to Kirschke et al. (2013), freshwater and geological sources including oceans contribute up to $27 \%$ of methane emissions from natural sources. Coastal and estuarine environments, in turn, may contribute up to $75 \%$ of global methane emission from brackish and marine environments combined (Hamdan \& Wickland 2016).

The main sink of methane in aerobic aquatic environments is bacterial methane oxidation. It can be responsible for the disposal of up to 80 or $90 \%$ of the available methane (Reeburgh et al. 1993, Guérin \& Abril 2007). However, aerobic methane oxidation in estuarine and coastal waters and its determining factors have received relatively little attention (Sherry et al. 2016). There are several factors that can affect

(C) The authors 2017. Open Access under Creative Commons by Attribution Licence. Use, distribution and reproduction are unrestricted. Authors and original publication must be credited. 
methane oxidation rates, including methane concentration (Jakobs et al. 2013, Mau et al. 2013, Gentz et al. 2014), temperature (Lofton et al. 2014), oxygen (Guérin \& Abril 2007), suspended particulate matter (Middelburg et al. 2002, Abril et al. 2007), light (Dumestre et al. 1999, Murase \& Sugimoto 2005) and salinity (de Angelis \& Scranton 1993). The lastmentioned factor is of particular interest regarding coastal freshwaters and estuaries. These areas represent mixing zones of fresh and marine water and thus are characterized by a dynamic gradient of salinity. Moreover, these environments are likely to be affected by the predicted climate change. So, for example, environmental transformations such as alterations in river discharge (Peterson et al. 2002, Wagner et al. 2011) and sea level rise (Rahmstorf 2007) would lead to the relocation of the estuarine (mixing) area with subsequent salinity stress for the local coastal ecosystems.

Most known methane oxidizing bacteria (MOB) have been isolated from non-saline environments (soils, sediments and lakes) (Hanson \& Hanson 1996, Khmelenina et al. 1999); however, there are some examples of $\mathrm{MOB}$ isolated from marine environments (Hirayama et al. 2013, Tavormina et al. 2015, Vekeman et al. 2016) and other hypersaline environments (Trotsenko \& Khmelenina 2002). MOB adapted to high salinity and/or $\mathrm{pH}$ values are geno- and phenotypically different from the inhabitants of freshwater environments with neutral $\mathrm{pH}$ values and have been described as new species (Khmelenina et al. 2010). However, irrespective of their taxonomic affiliation, halophilic and halotolerant MOB synthesize the same spectrum of compatible solutes, mostly the amino acid ectoine (Khmelenina et al. 2010). These solutes balance the osmotic pressure of the surrounding medium and maintain cell turgor pressure.

In addition to investigations of the ecophysiology of single strains, there are more recent studies on gene abundance and expression patterns along a salinity gradient, indicating that adaptation to a salinity change can also occur at a community level (Fortunato \& Crump 2015, Deng et al. 2017). Furthermore, Sherry et al. (2016) showed that the range of growth conditions (including salinity) of environmental samples is broader than those of the single strains.

Compared to knowledge on the osmoadaptation mechanisms of the halophilic and halotolerant MOB and the effect of salinity on their community composition, relatively little is known about resistance of MOB to changing salinity and its effect on methane oxidation rates. Most of the studies on MOB tolerance to salinity have been performed with soil MOB affected by ammonium and to a lesser extent by other salts (King \& Schnell 1998 and references therein, Bissett et al. 2012). The fate of freshwater non-methanotrophic bacteria in saline aquatic environments has mainly been studied on pathogenic microorganisms (Hrenovic \& Ivankovic 2009, Hatha et al. 2012). However, it has been shown in several studies that a salinity increase in river estuaries is followed by a decrease in methane oxidation rates (de Angelis \& Scranton 1993, Osudar et al. 2015, Sherry et al. 2016). This presumably happens due to osmotic stress in freshwater methanotrophic bacteria (Hanson \& Hanson 1996). At the same time, most studies report that microbial methane oxidation is already significantly reduced at salinities $<10$ (Abril \& Borges 2005), while Osudar et al. (2015) also observed relatively high methane oxidation rates at higher salinities. The variety of factors affecting methane oxidation in situ obstructs the assessment of the individual effect of salinity, thus revealing the necessity for additional laboratory experiments. Effect of decreasing salinity on marine $\mathrm{MOB}$, according to our knowledge, has received even less scientific attention.

In this study, we assessed the effect of an increase and decrease in salinity on the methanotrophic activity of freshwater and marine $\mathrm{MOB}$, respectively. We expected that different MOB species would have different salinity resistance; hence, experiments were conducted with pure cultures of various MOB as well as with environmental water samples to test the sensitivity of different MOB communities to salinity stress. Considering the complexity of bacterial response to osmotic shock (i.e. short- and long-term responses) and in order to better simulate the dynamics of the mixing of fresh and marine water that characterizes estuaries, we also performed experiments in which salinity was altered gradually, thereby expecting to attenuate osmotic stress for the bacterial cells.

\section{MATERIALS AND METHODS}

\section{Sample material}

Experiments were conducted with environmental samples (from the Elbe River and North Sea) and with methanotrophic cultures. The Elbe River water samples were collected near Hamburg at Elbe km EC 659; North Sea samples were collected at Helgoland Island (German Bight, North Sea). We sampled from surface waters $(1 \mathrm{~m}$ below the surface) with an UWITEC water sampler. Samples were stored for a maximum of $2 \mathrm{~d}$ at $4^{\circ} \mathrm{C}$ in the dark. 
Methanotrophic cultures were grown with modified nitrate mineral salt (NMS) medium (Whittenbury et al. 1970) buffered with $10 \mathrm{mM} \mathrm{HEPES}$ and $0.15 \mathrm{mM} \mathrm{PO}_{4}$, under an atmosphere of $50 \% \mathrm{CH}_{4}$ and $50 \%$ air. They were grown in glass desiccators at $18^{\circ} \mathrm{C}$ in the dark. The strains (Methylovulum sp. and Methylomonas sp.) had been isolated from the Elbe at $\mathrm{km}$ EC 659. The isolate Methylovulum sp. has been tentatively described as $97 \%$ similar to Methylovulum psychrotolerans and Methylomonas sp. was $97 \%$ similar to Methylomonas lenta (I. Bussmann et al. unpubl. data). Pure cultures of Methylosinus trichosporium and Methylobacter luteus were obtained from DSMZ and NBRC, the German and Scottish culture collections, respectively. For the experiments, colonies were scraped from agar plates, incubated for approximately $1 \mathrm{wk}$ in fluid medium in cell culture bottles (Nunc) to an optical density (OD) of approximately 0.5 and then transferred into the different experimental setups. Different setups in each specific experiment represented samples of the same origin (i.e. the same bacterial culture) but with altered salinity (e.g. 0, 1, 3 PSU etc.). Abbreviated names of all the experiments with dates and short descriptions are summarized in Table 1.

\section{Determination of the methane oxidation rate}

Samples were filled bubble-free into $120 \mathrm{ml}$ glass serum bottles, capped with black rubber stoppers, and sealed with an aluminum crimp. To eliminate agents that inhibit methane oxidation (such as soap), the bottles and stoppers underwent extensive chemical cleaning before use, as suggested by Osudar et al. (2015). Each experimental setup was per- formed with 3 to 5 replicates. As the experimental manipulations reduced the natural methane concentration, we added unlabeled methane to all setups. Amounts of added methane were well above those expected in situ to avoid methane depletion and eliminate methane concentration as a potentially affecting factor. Final methane concentration in experiments with $\mathrm{MOB}$ cultures ranged from 0.1 to $0.2 \mathrm{mmol} \mathrm{l}^{-1}$. In most of the fresh and marine water experiments final methane concentration ranged from approximately 150 to $1000 \mathrm{nmol} \mathrm{l}^{-1}$. In each specific experiment, however, variation in the concentration of dissolved methane between different setups did not exceed 9\%. This variation was caused by the small dissimilarity of added amounts of methane in combination with the different solubility of methane at different salinities. Unfortunately, in Expts IS-FW-4 and IS-MW-4 the methane addition failed, and so these experiments were conducted with concentrations of approximately $20 \mathrm{nmol}$ $1^{-1}$. Methane oxidation (MOX) rates were measured following a radiotracer technique using tritiated methane (American Radiolabeled Chemicals; $20 \mathrm{Ci}$ $\mu \mathrm{mol}^{-1}$ ) (Bussmann et al. 2015). Diluted tracer (0.1 ml, $2 \mathrm{kBq} \mathrm{m} \mathrm{m}^{-1}$ ) was added to the samples, which were then vigorously shaken and incubated in the dark at a temperature of $18^{\circ} \mathrm{C}$. MOB from the Elbe River and the North Sea were incubated for 20 to $24 \mathrm{~h}$; pure cultures were incubated for $5 \mathrm{~h}$. After incubation, MOX was stopped by adding $0.3 \mathrm{ml}$ of $25 \% \mathrm{H}_{2} \mathrm{SO}_{4}$ (for samples with salinity $>10$ ) or $5 \mathrm{~N}$ $\mathrm{NaOH}$ (for samples with salinity $\leq 10$ ). Controls were stopped before the addition of the tracer.

The MOX rate was determined by relating the radioactivity in the sample $\left(\mathrm{C}^{*} \mathrm{H}_{4}\right)$ to the radioactivity of the (tritiated) water $\left({ }^{*} \mathrm{H}_{2} \mathrm{O}\right)$ that was produced.

Table 1. Dates and experiments (abbreviated) performed, with numbers of the figures that illustrate the main results

\begin{tabular}{|lll|}
\hline & Immediate salinity change (IS) & Gradual salinity change (GS) \\
\hline Freshwater samples & IS-FW-1, Dec 2011; Fig. 1a & GS-FW 1, Feb 2014; Fig. 4c \\
& IS-FW-2, May 2012; Fig. 1b & \\
& IS-FW-3, Feb 2013; Fig. 1b & \\
& IS-FW-4, Jun 2013; Fig. 1a & \\
Marine water samples & IS-MW-1, May 2012; Fig. 3a & GS-MW-1, May 2014; Fig. 5 \\
& IS-MW-2, May 2012; Fig. 3b & GS-MW-2, Jun 2016; not shown \\
& IS-MW-3, Feb 2013; Fig. 3a & \\
Methylovulum sp. & IS-MW-4, Jun 2013; Fig. 3b & GS-methylovulum, Feb 2013; Fig. 4b \\
Methylomonas sp. & IS-methylovulum, Apr 2013; Fig. 2a & \\
Methylobacter luteus & IS-methylomonas, Jan 2013; Fig. 2b & GS-methylobacter, Mar 2013; Fig. 4a \\
Methylosinus trichosporium & IS-methylobacter, Jan 2013; Fig. 2a & \\
\hline
\end{tabular}


This ratio was multiplied by the ambient methane concentration $\left(\mathrm{CH}_{4}\right)$, corrected for the incubation time $(t)$ (Bussmann et al. 2015). The methane concentration in each bottle was determined by gas chromatography.

To make comparison among experiments easier, we compared the data on the basis of percentages. The initial MOX rate - without any salinity modifications - was set as $100 \%$.

Statistical significance of the MOX rate decrease due to the salinity change was determined using $t$ tests where initial MOX rate variables were compared with the MOX rate variables of a particular salinity setup (i.e. 30 PSU). When the MOX rates at several salinity setups had comparable mean values, these variables were pooled together and compared as a single group with the initial MOX rate variables. $t$-test results include the number of variables in each of 2 compared groups $\left(n_{1}\right.$ and $\left.n_{2}\right)$ and the p-value. When the normality test (Shapiro-Wilk) or the equal variance test were not passed we performed a MannWhitney rank sum test.

\section{Immediate change of salinity}

There are different definitions of salinity and salt concentration. In oceanography, salinity refers to the electronic conductivity of seawater, the so-called 'practical salinity unit' (PSU), which has no unit. Seawater is composed of many ions, but in physiological experiments and the discussion of microbial salt tolerance, this aspect is restricted to the concentrations of sodium chloride $(\mathrm{NaCl})$. In the course of this study, we decided to simplify these aspects to the following conversion scheme: $30 \mathrm{~g} \mathrm{l}^{-1} \mathrm{NaCl}=0.5 \mathrm{~mol} \mathrm{l}^{-1} \mathrm{NaCl}=$ $3 \% \mathrm{NaCl}=30 \%=30$ PSU.

The effect of changing salinity on the MOX rate was determined for Elbe River water, North Sea water and the methanotrophic cultures. To change the salinity of the samples, we either added $\mathrm{NaCl}$ to the samples (Expts IS-FW-1, IS-methylosinus, -methylobacter, -methylovulum and -methylomonas, Table 1) or mixed marine and freshwater to the required salinities (Expts IS-FW-2, -3, -4, IS-MW-1, -2, -3 and -4 , Table 1). Earlier investigations (de Angelis \& Scranton 1993) had shown that there was no difference between these manipulations.

For the mixing experiments, bacteria were separated from riverine and marine samples (3 l) by filtering them onto 5 and $0.2 \mu \mathrm{m}$ filters. Afterwards they were resuspended in $30 \mathrm{ml}$ of the original water. The sterile filtered riverine and marine waters were mixed to the required salinities $(1,3,5,10,20$ and 30 PSU). The bacteria were added to these mixtures to the initial concentration and the mixtures were distributed into triplicate $120 \mathrm{ml}$ glass bottles. In these bottles, the MOX rate was determined as described above. Salinity was measured using a Universal Pocket Meter (Multi 340i) with precision of $0.01 \mathrm{PSU}$.

\section{Gradual change of salinity}

In a next step, we wanted to test if $\mathrm{MOB}$ were able to adapt to a gradual change in salinity. Previous experiments had shown that M. luteus and Methylovulum sp. were sensitive to changes in salinity; thus, these 2 cultures were chosen for further experiments (Expts GS-methylobacter and GS-methylovulum). Additionally, we tested the natural MOB populations of Elbe and North Sea water (Expts GS-FW and GSMW, Table 1).

Triplicate samples $(250 \mathrm{ml})$ of methanotrophic cultures, riverine and marine water were incubated in $600 \mathrm{ml}$ Nunc cell culture bottles in a desiccator, as described above. Every day an aliquot was withdrawn and distributed into one $12 \mathrm{ml}$ ampoule to measure MOX and 1 subsample to measure salinity. To increase the salinity, $\mathrm{NaCl}$ was added afterwards directly to 3 replicates, while to another 3 replicates no salt was added. Thus, we had no dilution effect and the cell number in both setups would be expected to remain similar. The flasks were gently shaken to dissolve the salt and then incubated again in the desiccator. Within $8 \mathrm{~d}$, the salinity increased from 0.3 to 10 PSU.

To decrease the salinity of marine water samples, we added sterile filtered Milli-Q water to 3 replicates, while to another 3 replicates we added sterile filtered sea water. Thus all the samples were diluted, but with the same amount of water in both setups so the cell numbers would remain comparable. Within $8 \mathrm{~d}$, the salinity decreased from 32 to 22 PSU.

Methane concentrations in the ampoules used for MOX measurements in all setups exceeded $200 \mu \mathrm{mol}$ $\mathrm{l}^{-1}$, thus we avoided any possible limitation in methane, which might have affected MOX rates.

To normalize for growth (and increasing MOX rate), we calculated the ratio between the MOX without salinity change to the MOX with salinity change. Thus, a value around 1 indicates no influence of salinity, values $<1$ indicate an inhibiting effect of salinity and values $>1$ indicate stimulation through changed salinity. 

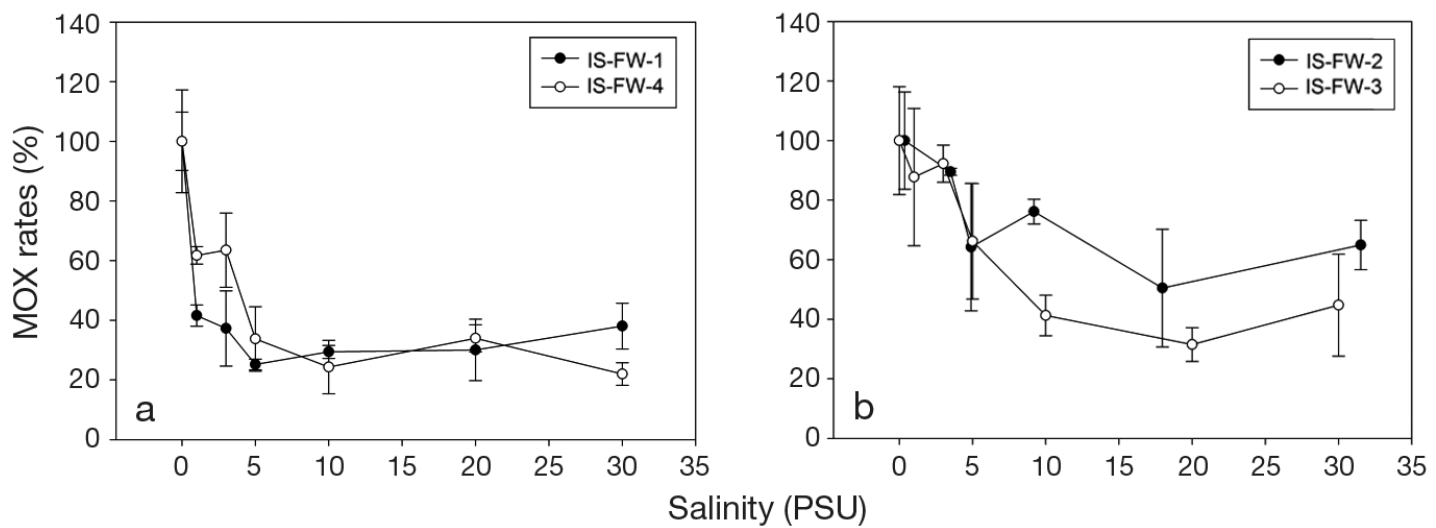

Fig. 1. Effect of immediate salinity increase on the methane oxidation (MOX) rates in samples from the Elbe River. (a) Expts ISFW-1 and IS-FW-4 and (b) Expts IS-FW-2 and IS-FW-3 (see Table 1). The initial MOX rate at a salinity of 0 was set as $100 \%$. Measurements of methane oxidation rates were performed in triplicate; means \pm SD are shown

\section{RESULTS}

\section{Immediate change of salinity}

In a first step, we tested the influence of an immediate increase in salinity (from approximately 0 to 30 ) on the MOX rate in a natural methanotrophic population in Elbe water. In all experiments (IS-FW-1 to IS-WF-4), the immediate salinity increase resulted in a decrease of MOX rates (Fig. 1). In Expts IS-FW-1 and IS-FW-4, the increase of salinity to 1 PSU led to a steep drop in the MOX rate, to 40 and $60 \%$ of the initial rate, respectively ( $t$-test IS-FW- $1: n_{1,2}=3, \mathrm{p}<$ 0.001; IS-FW-4: $n_{1,2}=3, \mathrm{p}=0.019$ ) (Fig. 1a). At salinities 5 to $30 \mathrm{PSU}, \mathrm{MOX}$ rates declined to $25-40 \%$ of the initial rate ( $t$-test IS-FW-1: $n_{1}=3, n_{2}=12, \mathrm{p}<0.001$; IS-FW-4: $n_{1}=3, n_{2}=12, p=0.012$ ). Initial methane concentrations were 160 and $20 \mathrm{nmol} \mathrm{l}^{-1}$, respectively. The initial MOX rates were approximately $2 \mathrm{nmol} \mathrm{l}^{-1} \mathrm{~h}^{-1}$. In Expts IS-FW-2, MOX rates declined up to a salinity of 5 PSU, where they reached a plateau and did not change significantly up to salinity of $30 \mathrm{PSU}$, varying from 51 to $76 \%$ ( $t$-test, $n_{1}=3$, $n_{2}=12, p=0.004$ ) (Fig. 1b). In Expt IS-FW-3, MOX rates declined up to a salinity of $10 \mathrm{PSU}$, where they reached a plateau varying from 32 to $45 \%$ ( $t$-test, $n_{1}$ $=3, n_{2}=8, p<0.001$ ) (Fig. 1b). Initial methane concentrations were 190 and $950 \mathrm{nmol} \mathrm{l}^{-1}$, respectively. The MOX rates were 11 to $13 \mathrm{nmol} \mathrm{l}^{-1} \mathrm{~h}^{-1}$. Thus, there seemed to be a sensitive and less sensitive response (Fig. 1a and Fig. 1b, respectively) of the freshwater samples to an immediate increase of salinity.

With different methanotrophic cultures (Methylosinus trichosporium, Methylobacter luteus, Methylovulum sp. and Methylomonas sp.) we also tested the influence of increasing salinity (Fig. 2). In the experiment with Methylovulum sp., MOX rates decreased proportionally to salinity and reached $23 \%$ at salinity 10 PSU ( $t$-test, $n_{1,2}=3, \mathrm{p}<0.001$ ) (Expt IS-methylovulum; Fig. 2a). At salinity of 30 PSU, the MOX rate fur-

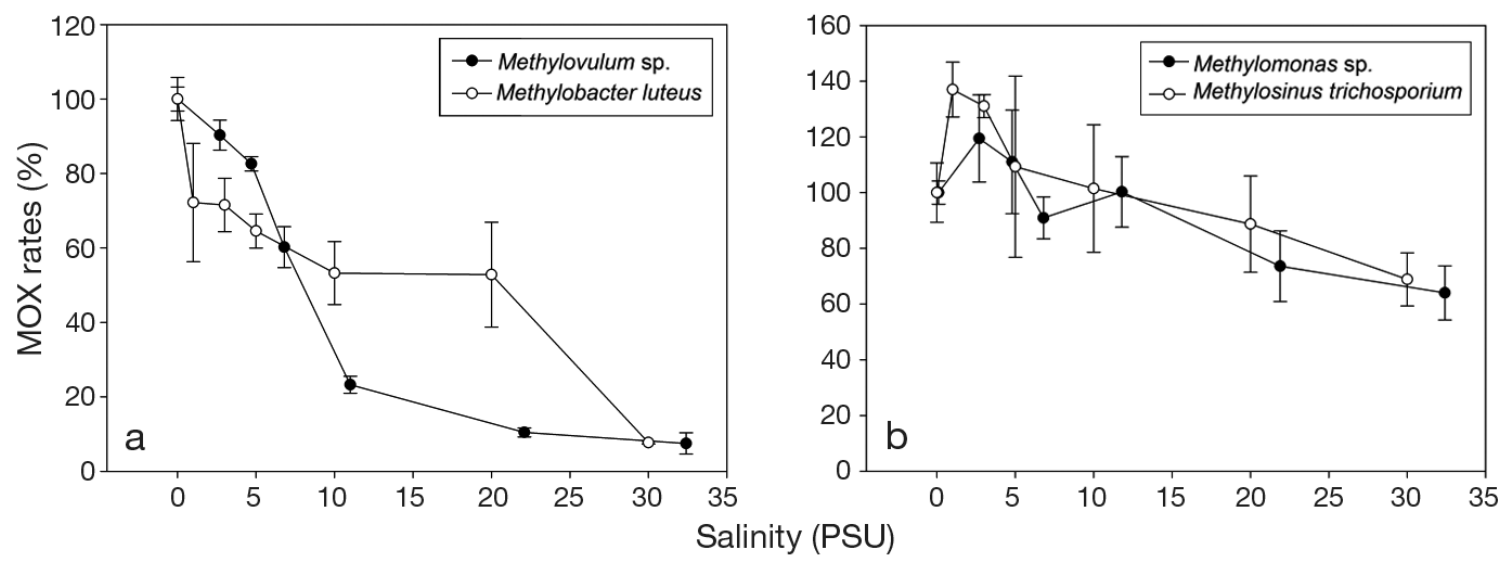

Fig. 2. Effect of immediate salinity increase on the methane oxidation (MOX) rates of methanotrophic cultures: (a) Methylovulum sp. and Methylobacter luteus and (b) Methylomonas sp. and Methylosinus trichosporium (see Table 1). The initial MOX rate at a salinity of 0 was set as $100 \%$. Measurements of methane oxidation rates were performed in triplicate; means \pm SD are shown 

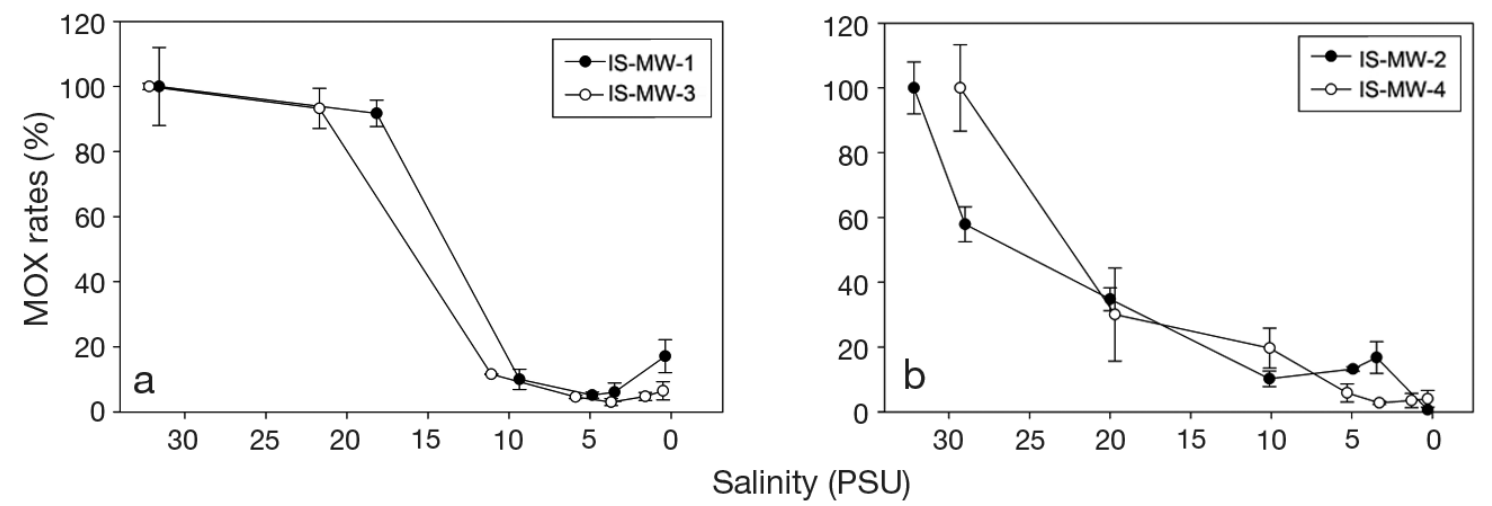

Fig. 3. Effect of immediate salinity decrease on the methane oxidation (MOX) rates for the marine water samples. The initial MOX rate at a salinity of 30 was set as $100 \%$ and, for better comparison with Fig. 2, the $x$-axis is displayed in reverse direction. (a) Expts IS-MW-1 and IS-MW-3 and (b) Expts IS-MW-2 and IS-MW-4 (see Table 1). Measurements of methane oxidation rates were performed in triplicate; means $\pm \mathrm{SD}$ are shown

ther declined to $8 \%\left(t\right.$-test, $\left.n_{1,2}=3, \mathrm{p}<0.001\right)$. In the experiment with $M$. luteus, the MOX rate at salinities from 1 to 20 PSU dropped to $53-72 \%\left(t\right.$-test, $n_{1}=3$, $n_{2}=15, \mathrm{p}=0.001$ ) (Expt IS-methylobacter; Fig. 2a). At salinity $30 \mathrm{PSU}$, the MOX rate abruptly dropped to $8 \%$ ( $t$-test, $\left.n_{1,2}=3, \mathrm{p}<0.001\right)$. In contrast, $M$. trichosporium (Expt IS-methylosinus) and Methylomonas sp. (Expt IS-methylomonas) strains showed variable MOX rate fluctuations, including an increase of MOX rates at salinities from 1 to 5 PSU. Only at salinity of 30 PSU did the MOX rate decrease to approximately $65 \%$ in both experiments ( $t$-test, IS-methylosinus: $n_{1,2}=3, \mathrm{p}=0.020$; IS-methylomonas: $n_{1,2}=3$, $\mathrm{p}=0.018$ ) (Fig. 2b). Thus, the response of methanotrophic cultures to salinity increase differed depending on the culture.

With marine methanotrophic populations from North Sea water we tested the influence of decreasing salinity. In 2 experiments at salinities of 30 and $20 \mathrm{PSU}$, the MOX rates stayed stable (Expts IS-MW1 and IS-MW-3; Fig. 3a). At salinities < 15 PSU, the MOX rate declined to $10-12 \%$ ( $t$-test, IS-MW- $1: n_{1}=$ $3, \mathrm{n}_{2}=12, \mathrm{p}<0.001$; IS-MW-3: $n_{1}=3, n_{2}=12, \mathrm{p}=$ $0.009)$. In these experiments, the final methane concentrations were 300 and $950 \mathrm{nmol} \mathrm{l}^{-1}$, respectively. The corresponding initial MOX rates were between 9 and $11 \mathrm{nmol}^{-1} \mathrm{~h}^{-1}$. In Expts IS-MW-2 and IS-MW-4, at a salinity of $20 \mathrm{PSU}$, the MOX rate decreased to $30-35 \%$ of the initial rate ( $t$-test IS-MW-2: $n_{1,2}=3, \mathrm{p}$ $<0.001$; IS-MW-4: $n_{1,2}=3, \mathrm{p}<0.003$; Fig. 3b). At salinities < $10 \mathrm{PSU}, \mathrm{MOX}$ rates declined to $1-17 \%(t$ test IS-MW-2: $n_{1}=3, n_{2}=13, \mathrm{p}=0.011$; IS-MW-4: $n_{1}$ $\left.=3, n_{2}=15, \mathrm{p}<0.001\right)$. The final methane concentrations were 360 and $20 \mathrm{nmol} \mathrm{l}^{-1}$, respectively. The corresponding initial MOX rates were 3 and $0.2 \mathrm{nmol} \mathrm{l}^{-1}$ $\mathrm{h}^{-1}$, respectively. Thus, there also seemed to be a sen- sitive and less sensitive response (Fig. 3a and Fig. 3b, respectively) of the marine samples to an immediate decrease of salinity, as in the freshwater samples.

\section{Gradual change of salinity}

In this set of experiments, we tested if the observed sensitivity to changes in salinity could be reduced when the increase or decrease occurred gradually over $10 \mathrm{~d}$.

As shown in the previous experiments, M. luteus and Methylovulum sp. were sensitive to an increase in salinity from 0 to 10 PSU (Fig. 2a). However, if we gradually increased salinity by $1.25 \mathrm{PSU} \mathrm{d}^{-1}$, the ratio between the MOX rate with and without salt addition (MOX rate +salt $_{\text {/ }}$ MOX control $_{1}$ ) remained around 1. Thus, $M$. luteus was able to adapt and its activity remained stable and comparable to the control without salt addition (Expt GS-methylobacter; Fig. 4a). In contrast, in the experiment with Methylovulum sp., the ratio between MOX rates with and without salt addition was stable up to a salinity of 3 PSU, but then declined to almost 0. Thus, Methylovulum sp. was not able to adapt to this gradual increase of salinity (Expt GS-methylovulum; Fig. 4b). Natural Elbe River water showed the same pattern as M. luteus with the population adapting to the gradual salinity increase (Expt GS-FW; Fig. 4c). However, on Days 6 and 7 with salinities of 7.7 and 9.2 PSU, we observed strong variability.

The gradual decrease of salinity from 32 to 22 PSU for marine water samples resulted in an increase of MOX rates in both experiments (GS-MW-1 and GS-MW-2). In the first experiment (GS-MW-1), the ratio between the MOX rate with and without 
salt dilution (MOX rate $_{- \text {salt }} / \mathrm{MOX}_{\text {control }}$ ) increased gradually from 1 at the beginning of incubation to approximately 3.5 on Day 9 of incubation (Fig. 5). The second experiment confirmed this pattern. At salinities from 30 to 28 , the ratio was around 1 , but it increased to an average ratio of $2.2 \pm 0.7$ at salinities from 27 to 22 .
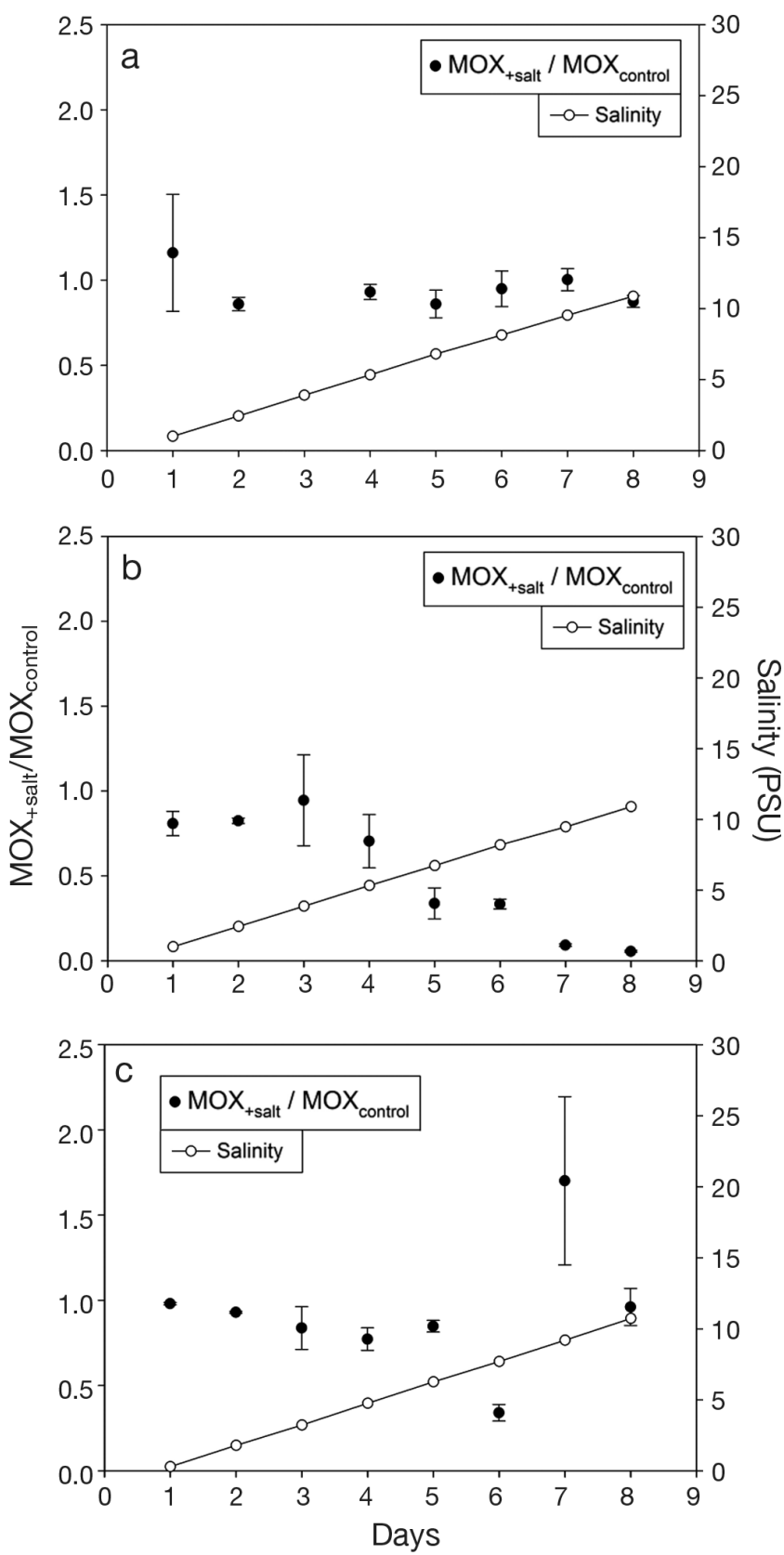

Fig. 4. Effect of gradual salinity change on the methane oxidation (MOX) rates for the (a) Methylobacter luteus culture, (b) Methylovulum sp. culture and (c) samples from the Elbe River. The ratio between MOX rate with and without salt addition is shown. Three replicate cultures or water samples were manipulated; means $\pm \mathrm{SD}$ are shown

\section{DISCUSSION}

In our study, we investigated the effect of salinity change on methane oxidation in different methanotrophic cultures, as well as in natural methanotrophic populations of freshwater and marine environments. We also included a temporal aspect, i.e. attenuation of osmolytic shock due to a gradual change of salinity.

\section{Response of MOB cultures to increasing salinity}

In our experiments on the effects of salinity change on different methanotrophic strains, we chose 2 strains, which have been isolated from the river Elbe (Methylovulum sp. and Methylomonas sp.). These riverine strains are important, because they experience changes in salinity when the river enters the sea. With a monooxygenase intergenic spacer analysis (MISA) fingerprinting method we could also show that these 2 strains are important members of the methanotrophic population (Schaal 2016). Knowledge of the specific ecology of Methylomonas species is currently limited. Indirect immunofluorescence studies suggest that Methylomonas species are common in surface sediments and the water columns of various fresh and brackish water environments and swampy soils (Bowman 2015). Optimal conditions for our Methylomonas strain ('Elbe A') were as follows: temperature 10 to $15^{\circ} \mathrm{C}$ and maximal $\mathrm{NaCl}$ concentration $0.5 \mathrm{~g} \mathrm{l}^{-1}$ (I. Bussmann et al. unpubl. data). Methylovulum strains are known to be neutrophilic, mesophilic and psychrotolerant (Bowman 2015). Optimal temperature for our strain ('Elbe 1') was 10

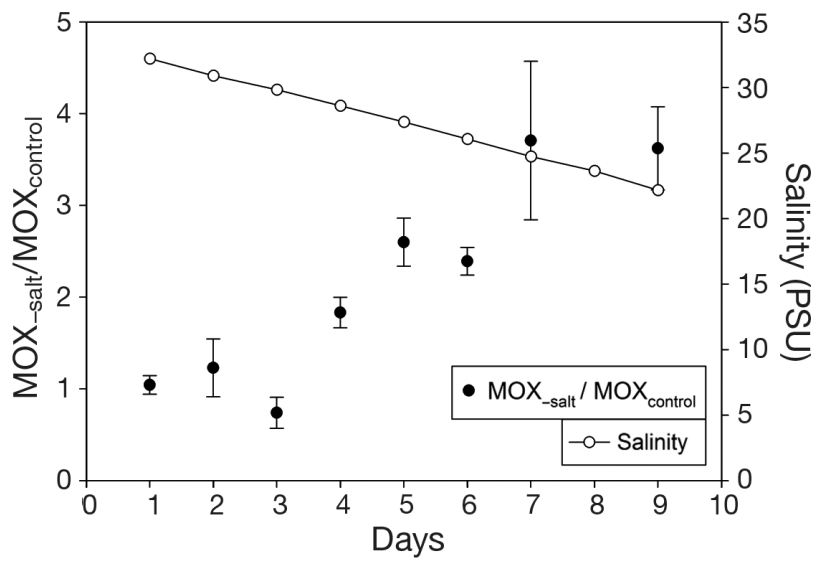

Fig. 5. Effect of gradual salinity change on the methane oxidation (MOX) rates of marine water samples (GS-MW-1). The ratio between the MOX rate with addition of MQ-water and addition of sea water is shown. Three replicate water samples were manipulated; means \pm SD are shown 
to $15^{\circ} \mathrm{C}$ and the maximal $\mathrm{NaCl}$ concentration $<0.5 \mathrm{~g}$ $1^{-1}$ (I. Bussmann et al. unpubl. data). We also wanted to broaden our spectrum to the Methylobacter group with Methylobacter luteus as type species and also have a type II MOB (Methylosinus trichosporium type IIa). Methylobacter species are mesophilic, and most strains grow in the range of 15 to $40^{\circ} \mathrm{C}$, with optimal growth occurring at about $30^{\circ} \mathrm{C}$. All Methylobacter strains are non-halophilic. The estuarine species Methylobacter marinus grows optimally with about $0.1 \mathrm{M} \mathrm{NaCl}$ in tap water. $M$. trichosporium has been isolated mostly from freshwater environments, but there are also some references to marine and brackish isolations (Heyer et al. 2002, Knief 2015). The usage of $4 \mathrm{MOB}$ strains for our experiments on sensitivity to salinity changes certainly cannot reflect the whole physiological range of cultivated methanotrophic strains, and further experiments with more methanotrophic strains, especially marine ones would be interesting. This study can be regarded as a first step towards further investigations on the salinity sensitivity/resistance of MOB.

Two of the investigated strains ( $M$. luteus and $M e-$ thylovulum sp.) were sensitive to an initial change of salinity (Fig. 2a). At salinities of 10 PSU, only 50 and $20 \%$ of the initial activity, respectively, was detected (Table 2). In contrast, Methylomonas sp. and M. trichosporium were resistant to the first osmolytic shock. When salinity increased gradually (1.2 PSU $\mathrm{d}^{-1}$ ), the previously sensitive $M$. luteus could adapt (probably by producing osmolytes), while Methylovulum sp. still could not cope.

Besides testing for activity (as in this study), strain descriptions normally use the parameter 'growth', i.e. whether the cultures produce colonies on agar plates or turbidity in fluid medium over a time span of approximately $3 \mathrm{wk}$. Bacterial growth occurs only if the 'activity' or dissimilatory processes produce enough energy for cell division. Inevitably, the 'very sensitive' strain Methylovulum sp. also did not grow at salinities > 2.5 PSU (I. Bussmann et al. unpubl. data). The 'moderately sensitive' $M$. luteus, which was able to adapt its activity to a gradual increase of salinity, still failed to grow at salinities > 2.5 PSU (I. Bussmann et al. unpubl. data). The more resistant Methylomonas sp., however, did grow at salinities up to 10 PSU (growth of $M$. trichosporium was not determined). Thus, our observed responses of methanotrophic activity in fluid medium were also reflected in the growth response on solid medium (Table 2). However, it has to be kept in mind that, to our knowledge, it is still unknown how the medium (fluid versus solid) influences the sensitivity of bacterial cultures to environmental changes.

In a recent study, Ho et al. (2013) linked functional traits and ecological characteristics of methanotrophs to their life strategies. Comparing their classification with our results, we agree that Methylobacter strains belong rather to the 'non-stress-resistant' category, while Methylosinus strains can be classed as 'stressresistant'. In contrast, the Methylomonas strain which we found to be stress-resistant was characterized as 'non-stress-resistant' in the study of Ho et al. (2013). Not much is yet known about the ecological characteristics of Methylovulum strains.

\section{Response of freshwater MOB communities to increasing salinity}

The whole methanotrophic community of river water was exposed to increasing salinities in Expts IS-FW$1,-2,-3$ and -4 . Here again, we found a similar pattern with a very sensitive community (Expts IS-FW-1

Table 2. Response of methanotrophic cultures to increasing salinity; nd: not determined. Methane oxidation (MOX) rates without modifications in salinity were set as $100 \%$

\begin{tabular}{|lccc|}
\hline & $\begin{array}{c}\text { Very sensitive } \\
\text { Methylovulum sp. }\end{array}$ & $\begin{array}{c}\text { Moderately sensitive } \\
\text { Methylobacter luteus }\end{array}$ & $\begin{array}{c}\text { Resistant } \\
\text { Methylomonas sp., } \\
\text { Methylosinus trichosporium }\end{array}$ \\
\hline Activity at initial change of salinity & 5 PSU: $80 \%$ & 5 PSU: $65 \%$ & 5 PSU: $100 \%$ \\
Activity with gradual change & 10 PSU: $20 \%$ & 10 PSU: $50 \%$ & 10 PSU: $100 \%$ \\
of salinity (0-10) & No adaptation & Can adapt & nd \\
Growth with initial change of salinity & 5 PSU: $95 \%$ & 10 PSU: $95 \%$ & 5 PSU: yes/nd \\
(I. Bussmann et al. unpubl. data) & 10 PSU: $\%$ & 10 PSU: no & 10 PSU: yes/nd \\
Expected behavior in estuarine & 5 PSU: no & Active, growth \\
environment & 10 PSU: no & Low activity & bosible \\
\hline
\end{tabular}


and -4 ; Fig. 1a) and a moderately sensitive one (Expts IS-FW-2 and -3 ; Fig. 1b). When a gradual increase of salinity was allowed, the community seemed to be resistant and no reduction in activity was observed (Expt GS-FW; Fig. 4c).

We hypothesized that other environmental stressors, such as methane concentration, could affect the sensitivity of the MOB community. However, we encountered very sensitive populations not only in Expt IS-FW-4 (Fig. 1a), where final methane concentrations were relatively low $\left(20 \mathrm{nmol} \mathrm{l}^{-1}\right)$ but also in Expt IS-FW-1 (Fig. 1a), which had elevated methane concentrations $\left(160 \mathrm{nmol} \mathrm{l}^{-1}\right)$. Thus, we assume that methane concentration had no effect on the sensitivity of MOB populations or at least was not the only affecting factor. In the experiments with the initially higher MOX rates, the MOB population was more salinity-resistant. We assumed that the community composition at the start of the experiment influences the sensitivity. Also, temperature may have an effect on salinity resistance, as optimal temperature can mitigate the effect of salinity stress on freshwater bacteria (McArthur 2006). Though all the experiments were performed at the same incubation temperature $\left(18^{\circ} \mathrm{C}\right)$, we expected to observe more salinity-resistant $\mathrm{MOB}$ communities in the water samples collected in the warmer months. Lucas et al. (2016) showed that in situ temperature is the main factor that shapes bacterial community composition in the German Bight. However, no correspondence between sampling period and salinity tolerance was observed. Unfortunately, we did not allow for a full set of combination of the factors mentioned. So, for example, it would be interesting to investigate salinity tolerance in combination with methane and incubation temperature under optimal and suboptimal conditions. A study on the diversity of methanotrophic bacteria in the Elbe estuary showed that salinity and temperature explained the biggest part of the methanotrophic diversity (Schaal 2016). Finally, the influence of the non-methanotrophic members of the overall microbial community on methanotrophic activity (Ho et al. 2014) and presumably sensitivity of the methanotrophs should also be considered in future investigations.

Variance in salinity tolerance between different MOB strains is well documented (Khmelenina et al. 2010) and was also shown in the present study. The Elbe River estuary is a very dynamic aquatic system (Osudar et al. 2015), and fluctuations in bacterial community composition followed by the influence of various factors or dispersion from other aquatic and terrestrial environments seem quite possible. For example, a study on MOB community composition in sediments of the Tyne estuary showed that some of the observed 'extremophilic' types originate from various and sometimes remote sites (Sherry et al. 2016). Thus, when methanotrophic bacteria are transported with the river into the marine environment, some species will not be able to stay active and will not grow. If the mixing process is slow, other methanotrophs will be able to adapt. This hypothesis is supported by Painchaud et al. (1995), who observed strong bacterial mortality in fast-mixing estuaries (i.e. hours), whereas no mortality was observed when the mixing occurred within days.

\section{Response of marine MOB communities to decreasing salinity}

To date, only a few marine methanotrophs have been described (Hirayama et al. 2013, 2014, Tavormina et al. 2015, Vekeman et al. 2016) and not much is known about their ecological capabilities.

Our experiments with an initial change of salinity point towards a 'moderately sensitive' (Expts ISMW-1 and -3; Fig. 3a) and a 'very sensitive' (Expts ISMW-2 and -4 ; Fig. 3b) population of marine methanotrophs, as also shown for the freshwater experiments. At salinity of approximately 20 PSU, 'moderately sensitive' MOB communities stayed rather active (with an average of $93 \pm 1 \%$ activity), while the activity of the 'very sensitive' communities substantially decreased (32 $\pm 3 \%$ activity). In all 4 experiments, activity at salinity $\leq 10$ PSU was reduced to an average of $8 \pm 6 \%$. The 10 PSU seems to be a threshold, as the lower limit of salinity for growth of the marine methanotrophs is $<1 \%$ (approximately 10 PSU) (Hirayama et al. 2013, Tavormina et al. 2015).

Surprisingly, when salinity was gradually decreased from 32 to $22 \mathrm{PSU}$, the activity of the marine methanotrophic population increased by 2 to 3.5 times. Assuming a salinity of 32 to 35 PSU for marine environments, marine methanotrophs have a salinity optimum, which is below the marine salinity range. The optimal salinity ranges are 15 to 20 (Lees et al. 1991), 20 (Tavormina et al. 2015) and 20 to 30 (Hirayama et al. 2013). Even enrichment media for marine heterotrophs are not fully marine, at 24 and $26 \mathrm{~g} \mathrm{NaCl}$ (approximately 24 and 26 PSU) (Süß et al. 2004, Hahnke et al. 2015).

Comparing the marine and the freshwater methanotrophic populations, the freshwater populations seem to have a broader range of salinities at which they can maintain a certain level of activity. Even the 
'very sensitive' populations attain a level of approximately $30 \%$ and the 'moderately sensitive' ones approximately $50 \%$ at salinity 30 PSU. In contrast, activity of the marine methanotrophic population at salinities $\leq 10$ drops to only $8 \pm 6 \%$.

In our study, we exposed pure cultures of freshwater MOBs as well as marine and freshwater natural populations to salinity stress. We found stressresistant strains, as well as more sensitive ones. The reactions of the natural communities could also be divided into stress-resistant and stress-sensitive responses. The responses of the communities differed between sampling times. We could not assign methane concentration to this variable sensitivity. Thus, we hypothesized that the response on the community level is determined by the community composition, i.e. the ratio of stress-resistant and stress-sensitive MOB strains and potentially non-methanotrophic bacteria, which may also have an impact on the methanotrophic activity and sensitivity (Ho et al. 2014). Unfortunately, we were not able to investigate these effects at the community level. Other studies have shown that experimental modifications (on $\mathrm{Cu}$ and Fe content) do result in changes of the methanotrophic community (Chidambarampadmavathy et al. 2017). Salinity is known to be an important factor in shaping the native bacterial population. Salinity and associated factors play a role in controlling diversity and distribution of Archaea in estuarine sediments (Webster et al. 2015). And for MOB in soils, the soil salinity was responsible for the niche separations (Bissett et al. 2012). In addition, the frequency of disturbances as well as the site history are further important factors in assessing the resilience of the MOB community to changes in salinity (Ho et al. 2016).

Within an estuary, we assume that marine methanotrophs would be active down to a salinity of approximately 10 PSU, but only the moderately sensitive communities. In contrast, freshwater MOB seem to be more flexible and should be able to adapt to marine environments. However, as pointed out by Ho et al. (2016), in the long run, the indigenous population with more competitive traits will become an active part of a stable MOB population again.

\section{CONCLUSIONS}

In the present study, we showed that (1) pure cultures of freshwater MOBs as well as different MOB communities differ substantially regarding the effect of salinity on their methanotrophic activity; (2) marine water MOB communities are generally more sensitive to salinity decrease than freshwater MOB communities are to salinity increase; and (3) gradual salinity change can mitigate the influence of salinity on methanotrophic activity of $\mathrm{MOB}$ isolates and environmental MOB communities. The present research has shed some light on the effect of salinity change on methane oxidation in marine and freshwater environments, raising further questions to be answered in future investigations and emphasizing the complexity of the studied phenomena. The main questions that remain are: how long salinity-resistant MOB communities and isolates can survive and stay metabolically active at different salinities; how salinity controls the composition and methanotrophic activity of MOB communities; and how sustainable these communities are in the changing environment.

Acknowledgements. This study was part of the Helmholtz programme PACES, Topic 2. We also thank the crew of the F/S 'Ludwig Prandtl' for supporting the sampling operations on the Elbe River.

\section{LITERATURE CITED}

Abril G, Commariew MV, Guérin F (2007) Enhanced methane oxidation in an estuarine turbidity maximum. Limnol Oceanogr 52:470-475

Abril G, Borges AV (2005) Carbon dioxide and methane emissions from estuaries. In: Tremblay A, Varfalvy L, Roehm C, Garneau M (eds) Greenhouse gas emissions: fluxes and processes, hydroelectric reservoirs and natural environments. Springer, Berlin, p 187-207

Kastviken D, Tranvik LJ, Downing JA, Crill PM, EnrichPrast A (2011) Freshwater methane emissions offset the continental carbon sink. Science 331:50

Bissett A, Abell GC, Bodrossy L, Richardson AE, Thrall PH (2012) Methanotrophic communities in Australian woodland soils of varying salinity. FEMS Microbiol Ecol 80: 685-695

Bowman JP (2015) Methylococcaceae. In: Bergey's manual of systematics of Archaea and Bacteria. John Wiley \& Sons, Hoboken, NJ, p 1-8

* Bussmann I, Matousu A, Osudar R, Mau S (2015) Assessment of the radio ${ }^{3} \mathrm{H}-\mathrm{CH}_{4}$ tracer technique to measure aerobic methane oxidation in the water column. Limnol Oceanogr Methods 13:312-327

Chidambarampadmavathy K, Karthikeyan OP, Huerlimann R, Maes GE, Heimann K (2017) Responses of mixed methanotrophic consortia to variable $\mathrm{Cu}^{2+} / \mathrm{Fe}^{2+}$ ratios. J Environ Manage 197:159-166

* Cicerone RJ, Oremland RS (1988) Biogeochemical aspects of atmospheric methane. Global Biogeochem Cycles 2: 299-327

de Angelis MA, Scranton MI (1993) Fate of methane in the Hudson River and estuary. Global Biogeochem Cycles 7 : 509-523

*Deng Y, Liu Y, Dumont M, Conrad R (2017) Salinity affects the composition of the aerobic methanotroph community 
in alkaline lake sediments from the Tibetan Plateau. Microb Ecol 73:101-110

* Dumestre JF, Guézennec J, Galy-Lacaux C, Delmas R, Richard S, Labroue L (1999) Influence of light intensity on methanotrophic bacterial activity in Petit Saut Reservoir, French Guiana. Appl Environ Microbiol 65:534-539

Fortunato CS, Crump BC (2015) Microbial gene abundance and expression patterns across a river to ocean salinity gradient. PLOS ONE 10:e0140578

Gentz T, Damm E, Schneider von Deimling J, Mau S, McGinnis DF, Schlüter M (2014) A water column study of methane around gas flares located at the West Spitsbergen continental margin. Cont Shelf Res 72:107-118

Guérin F, Abril G (2007) Significance of pelagic aerobic methane oxidation in the methane and carbon budget of a tropical reservoir. J Geophys Res 112:G03006

* Hahnke RL, Bennke CM, Fuchs BM, Mann AJ and others (2015) Dilution cultivation of marine heterotrophic bacteria abundant after a spring phytoplankton bloom in the North Sea. Environ Microbiol 17:3515-3526

Hamdan LJ, Wickland KP (2016) Methane emissions from oceans, coasts, and freshwater habitats: new perspectives and feedbacks on climate. Limnol Oceanogr 61:S3-S12

‘ Hanson RS, Hanson TE (1996) Methanotrophic bacteria. Microbiol Rev 60:439-471

Hatha A, Chandran A, Asit M, Sherin V, Thomas A (2012) Influence of a salt water regulator on the survival response of Salmonella Paratyphi in Vembanadu Lake: India. In: Kumar Y (ed) Samonella: a diversified superbug. Intech Open Access Publishers, Rijeka, p 47-62

Heyer J, Galchenko VF, Dunfield PF (2002) Molecular phylogeny of type II methane-oxidizing bacteria isolated from various environments. Microbiology 148:2831-2846

Hirayama H, Fuse H, Abe M, Miyazaki M and others (2013) Methylomarinum vadi gen. nov., sp. nov., a methanotroph isolated from two distinct marine environments. Int J Syst Evol Microbiol 63:1073-1082

Hirayama H, Abe M, Miyazaki M, Nunoura T, Furushima Y, Yamamoto H, Takai K (2014) Methylomarinovum caldicuralii gen. nov., sp. nov., a moderately thermophilic methanotroph isolated from a shallow submarine hydrothermal system, and proposal of the family Methylothermaceae fam. nov. Int J Syst Evol Microbiol 64:989-999

Ho A, Kerckhof FM, Luke C, Reim A, Krause S, Boon N, Bodelier PLE (2013) Conceptualizing functional traits and ecological characteristics of methane-oxidizing bacteria as life strategies. Environ Microbiol Rep 5:335-345

Ho A, De Roy K, Thas O, De Neve J and others (2014) The more, the merrier: heterotroph richness stimulates methanotrophic activity. ISME J 8:1945-1948

Ho A, Brink E, Reim A, Krause SMB, Bodelier PLE (2016) Recurrence and frequency of disturbance have cumulative effect on methanotrophic activity, abundance, and community structure. Front Microbiol 6:1493

Hrenovic J, Ivankovic T (2009) Survival of Escherichia coli and Acinetobacter junii at various concentrations of sodium chloride. EurAsian Journal of Biosciences 3: 144-151

IPCC (2014) Climate change 2014: synthesis report. Contribution of Working Groups I, II and III to the Fifth Assessment Report of the Intergovernmental Panel on Climate Change. IPCC, Geneva

Jakobs G, Rehder G, Jost G, Kießlich K, Labrenz M, Schmale O (2013) Comparative studies of pelagic microbial methane oxidation within two anoxic basins of the central Baltic Sea (Gotland Deep and Landsort Deep). Biogeosciences Discuss 10:12251-12284

Khmelenina VN, Kalyuzhnaya MG, Sakharovsky VG, Suzina NE, Trotsenko YA, Gottschalk G (1999) Osmoadaptation in halophilic and alkaliphilic methanotrophs. Arch Microbiol 172:321-329

Khmelenina VN, Shchukin VN, Reshetnikov AS, Mustakhimov II, Suzina NE, Eshinimaev BT, Trotsenko YA (2010) Structural and functional features of methanotrophs from hypersaline and alkaline lakes. Microbiology 79:472-482

King GM, Schnell S (1998) Effects of ammonium and nonammonium salt additions on methane oxidation by Methylosinus trichosporium OB3b and Maine forest soils. Appl Environ Microbiol 64:253-257

Kirschke S, Bousquet P, Ciais P, Saunois M and others (2013) Three decades of global methane sources and sinks. Nat Geosci 6:813-823

Knief C (2015) Diversity and habitat preferences of cultivated and uncultivated aerobic methanotrophic bacteria evaluated based on pmoA as molecular marker. Front Microbiol 6:1346

LLees V, Owens NJ, Murrell JC (1991) Nitrogen metabolism in marine methanotrophs. Arch Microbiol 157:60-65

Lofton DD, Whalen SC, Hershey AE (2014) Effect of temperature on methane dynamics and evaluation of methane oxidation kinetics in shallow Arctic Alaskan lakes. Hydrobiologia 721:209-222

* Lucas J, Wichels A, Gerdts G (2016) Spatiotemporal variation of the bacterioplankton community in the German Bight: from estuarine to offshore regions. Helgol Mar Res 70:16

*Mau S, Blees J, Helmke E, Niemann H, Damm E (2013) Vertical distribution of methane oxidation and methanotrophic response to elevated methane concentrations in stratified waters of the Arctic fjord Storfjorden (Svalbard, Norway). Biogeosciences 10:6267-6278

McArthur JV (2006) Microbial ecology: an evolutionary approach. Academic Press, Burlington, MA

Middelburg J, Nieuwenhuize J, Iversen N, Høgh N and others (2002) Methane distribution in European tidal estuaries. Biogeochemistry 59:95-119

* Murase J, Sugimoto A (2005) Inhibitory effect of light on methane oxidation in the pelagic water column of a mesotrophic lake (Lake Biwa, Japan). Limnol Oceanogr 50:1339-1343

* Osudar R, Matouš A, Alawi M, Wagner D, Bussmann I (2015) Environmental factors affecting methane distribution and bacterial methane oxidation in the German Bight (North Sea). Estuar Coast Shelf Sci 160:10-21

*Painchaud J, Therriault JC, Legendre L (1995) Assessment of salinity-related mortality of freshwater bacteria in the Saint Lawrence Estuary. Appl Environ Microbiol 61: 205-208

Peterson BJ, Holmes RM, McClelland JW, Vörösmarty CJ and others (2002) Increasing river discharge to the Arctic Ocean. Science 298:2171-2173

Rahmstorf S (2007) A semi-empirical approach to projecting future sea-level rise. Science 315:368-370

Reeburgh W, Whalen S, Alperin M (1993) The role of methylotrophy in the global methane budget. In: Murrell JC, Kelly DP (eds) Microbial growth on C1 compounds. Intercept, Andover, p 1-14

Schaal P (2016) Diversity of methanotrophic bacteria in the Elbe Estuary. MSc thesis, Hochschule Bremerhaven

Sherry A, Osborne KA, Sidgwick FR, Gray ND, Talbot HM (2016) A temperate river estuary is a sink for methano- 
trophs adapted to extremes of $\mathrm{pH}$, temperature and salinity. Environ Microbiol Rep 8:122-131

Singh BK, Bardgett RD, Smith P, Reay DS (2010) Microorganisms and climate change: terrestrial feedbacks and mitigation options. Nat Rev Microbiol 8:779-790

Süß J, Engelen B, Cypionka H, Sass H (2004) Quantitative analysis of bacterial communities from Mediterranean sapropels based on cultivation-dependent methods. FEMS Microbiol Ecol 51:109-121

Tavormina PL, Hatzenpichler R, McGlynn S, Chadwick G, Dawson KS, Connon SA, Orphan VJ (2015) Methyloprofundus sedimenti gen. nov., sp. nov., an obligate methanotroph from ocean sediment belonging to the 'deep sea-1'clade of marine methanotrophs. Int J Syst Evol Microbiol 65:251-259

Trotsenko YA, Khmelenina VN (2002) Biology of extremo-

Editorial responsibility: Paul del Giorgio, Montreal, Quebec, Canada philic and extremotolerant methanotrophs. Arch Microbiol 177:123-131

*Vekeman B, Kerckhof FM, Cremers G, de Vos P and others (2016) New Methyloceanibacter diversity from North Sea sediments includes methanotroph containing solely the soluble methane monooxygenase. Environ Microbiol 18:4523-4536

Wagner A, Lohmann G, Prange M (2011) Arctic river discharge trends since $7 \mathrm{ka}$ BP. Global Planet Change 79:48-60

Webster G, O'Sullivan LA, Meng Y, Williams AS and others (2015) Archaeal community diversity and abundance changes along a natural salinity gradient in estuarine sediments. FEMS Microbiol Ecol 91:1-18

*Whittenbury R, Phillips K, Wilkinson J (1970) Enrichment, isolation and some properties of methane-utilizing bacteria. J Gen Microbiol 61:205-218

Submitted: September 19, 2016; Accepted: June 14, 2017 Proofs received from author(s): August 28, 2017 